\title{
Mathematics Science and Technology
}

mathematical methods, models and Algorithms in Science and Technology 
Proceedings of the Satellite Conference of ICM 2010

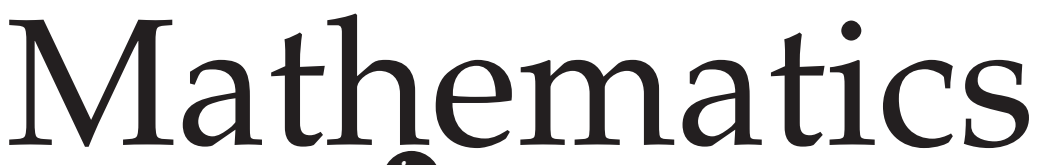
Science and Technology

Mathematical Methods, models and Algorithms in Science and Technology

India Habitat Centre \& India Islamic Cultural Centre, New Delhi, India

$14-17$ August 2010

Editors

A H Siddiqi

Sharda University, India

R C Singh

Sharda University, India

P Manchanda

Gurunanak Dev University, India 


\section{Published by}

World Scientific Publishing Co. Pte. Ltd.

5 Toh Tuck Link, Singapore 596224

USA office: 27 Warren Street, Suite 401-402, Hackensack, NJ 07601

UK office: 57 Shelton Street, Covent Garden, London WC2H 9HE

\section{British Library Cataloguing-in-Publication Data}

A catalogue record for this book is available from the British Library.

\section{Proceedings of the Satellite Conference of ICM 2010 MATHEMATICS IN SCIENCE AND TECHNOLOGY \\ Mathematical Methods, Models and Algorithms in Science and Technology}

Copyright $\odot 2011$ by World Scientific Publishing Co. Pte. Ltd.

All rights reserved. This book, or parts thereof, may not be reproduced in any form or by any means, electronic or mechanical, including photocopying, recording or any information storage and retrieval system now known or to be invented, without written permission from the Publisher.

For photocopying of material in this volume, please pay a copying fee through the Copyright Clearance Center, Inc., 222 Rosewood Drive, Danvers, MA 01923, USA. In this case permission to photocopy is not required from the publisher.

ISBN-13 978-981-4338-81-3

ISBN-10 981-4338-81-8

Printed in Singapore by B \& Jo Enterprise Pte Ltd 
This page is intentionally left blank 


\section{PREFACE}

This volume is based on selected talks - invited, thematic and contributory - delivered during the Satellite Conference of the International Congress of Mathematicians 2010 on Mathematics in Science and Technology, held in New Delhi, India, 14-17 August 2010, sponsored by ICM 2010; Department of Science and Technology (DST); National Board of Higher Mathematics (NBHM); Council of Scientific and Industrial Research (CSIR); Defense Research and Development organization (DRDO), Government of India; Sharda University, Greater Noida, India; Abdus Salam International Centre for Theoretical Physics, Trieste, Italy (a UNESCO centre); International Council of Industrial and Applied Mathematics (ICIAM); Commission of Development and Exchanges (CDE-IMU), and the Indian Society of Industrial and Applied Mathematics (ISIAM). The volume is divided into three parts; Part A contains Chaps. 1-8 based on invited talks by international experts, who have made valuable contributions in their fields of research. Part B, comprising of Chaps. 9-16, is based on thematic review papers by scholars actively engaged in the study of related areas. Four peer reviewed contributory talks are included as Chaps. 17-20 forming Part C.

Chapter 1 is the Dr. Zakir Husain award lecture by the recipient of the Dr. Zakir Husain award 2010, Prof. M. Zuhair Nashed, University of Central Florida, USA. In the technical part of his chapter, he presents the common thread among inverse problems, signal analysis and moment problems. This effort is related to the recovery of an object (function, signal or picture) from partial or indirect information about the object. He has provided a broad prospective on some aspects of this interaction with emphasis on ill-posed problems in signal processing.

In Chap. 2, Prof. Phoolan Prasad, along with one of his research collaborator, K. R. Arun, has presented a beautiful account of Kinetic Conservation Laws (KCL), or equations of evolutions for curves and surfaces with their application to a nonlinear wave front giving numerical simulation. In Chap. 3, Prof. V. Mehrmann, jointly with his co-workers J. Heiland and M. Schmidt has presented an interesting framework for the 
direct discretization of the input/output map of dynamical systems governed by linear partial differential equations with distributed inputs and outputs. Global error estimates and applications to the optimal control of partial differential equations, particularly for the 2D heat equation, are discussed. In Chap. 4, Prof. Pavel Exner has given a delightful description of the physical meaning of quantum graph models through analysis of their vertex coupling approximations.

Prof. R. Lozi of France, known for the strange attractor as the Lozi map, has given a lucid presentation on "Complexity Leads to Randomness in Chaotic Systems" in Chap. 5. In Chap. 6, Prof. N. Rudraiah has drawn the attention to certain important real world problems, where mathematical concepts can play important role. He highlights, among other topics, the role of mathematical modeling in nanotechnology. Prof. O. P. Bhutani, jointly with Lipika Chowdhary, presents a study on equivalence transformations of a Helmholtz-type equation in Chap. 7.

In Chap. 8, Prof. U. B. Desai and his research associates have focused on emerging areas of communication technology and the challenging mathematical problems in the area. Cognitive Radio (CR) is a challenging field of wireless communication. In this chapter, the authors have investigated the optimal power allocation problem for an orthogonal frequency division multiplexing based CR.

Part B comprises of eight thematic reviews, Chaps. 9-16. These are: 1. Inverse Problems of Parameter Identification in Partial Differential Equations (B. Jadamba, A. A. Khan and M. Sama); 2. Finite Element Methods for HJB Equations (M. Boulbrachene); 3. Dynamics and Control of Underactuated Space Systems (K. D. Kumar and Godard); 4. Some New Classes of Inverse Coefficient Problems in Engineering Mechanics and Computational Material Science Based on Boundary Measured Data (A. Hasanov); 5. Some Recent Developments on Mathematical Aspects of Wavelets (P. Manchanda and Meenakshi); 6. Relevance of Wavelets and Inverse Problems to Brain (A. H. Siddiqi, H. K. Sevindir, Z. Aslan and C. Yazici); 7. Wavelets and Inverse Problems (K. Goyal and M. Mehra); 8. Optimization Models for a Class of Structured Stochastic Games (S. K. Neogy, S. Sinha, A. K. Das and A. Gupta).

Chapter 9 deals with inverse problems which is a vibrant and fast progressing theme that has found numerous significant applications. Twelve methods to solve a class of inverse problems along with applications are discussed. New avenues of research in this field are indicated. The theme is quite relevant to emerging problems of science and technology. In Chap. 10, 
recent progress in the finite element approximation of HJB (HamiltonJacobi-Bellman) equations are reviewed and open problems are mentioned. Chapter 11 is devoted to the feasibility of achieving reliable formation control without the need for thrust in the radical or along-track direction. The advantages of the control method considered in this paper are validated via numerical simulations. Updated results are reviewed on the theme of relative motion control of multiple space craft formations using thrusters in fully actuated configuration.

In Chap. 12, three classes of inverse coefficient problems arising in engineering mechanics and computational material science are considered. The first problem is related to the determination of unknown elasto-plastic properties of a beam from limited number of torsional experiments. The second problem is related to the identification of elasto-plastic properties of a $3 \mathrm{D}$ body from spherical identification test while the third one relates to identification of unknown coefficient in the nonlinear bending equation. Besides the solutions of these problems, their applications are also discussed.

In Chap. 13, three theoretical aspects of wavelets are considered. These are (i) The effect of replacing the set of integers of translation parameters by its subset that is not a group in the definition of scaling function, an important ingredient of multi-resolution analysis known as the heart of wavelet theory. (ii) Consequences of replacing the set of real numbers by the set of positive real numbers in the definition of multi-resolution analysis. (iii) Properties of wavelets obtained by vector-valued multi-resolution analysis. Results obtained by these modifications are reviewed. Applications of wavelets and inverse problems, particularly to EEG (signal representing functioning of brain) are reviewed in Chap. 14. In Chap. 15, certain aspects of inverse problems and wavelets are discussed. Chapter 16 presents an updated description of optimization models for a class of Structured Stochastic Games.

Part C consists of four peer reviewed contributory chapters, 17-20. Chapter 17 by Q. J. Khan and M. Al-Lawatia develops a mathematical model of an interesting real world problem, namely Predator-Prey relations for mammals in a special situation. Chapter 18 by G. Röst deals with SEI model with varying transmission and mortality rate. Chapter 19 by B. S. Kushvah presents the study of Trajectories and Stability Regions. In Chap. 20, Wasu and Rajvanshi present their study of MHD flow past an infinite plate under the effect of gravity modulation.

A complete list of dignitaries and persons who participated actively in the conference is given at the end of this volume. 
We take this opportunity to thank all the funding agencies mentioned above, especially the authorities of Sharda University, honorable Mr. P. K. Gupta (Chancellor), Mr. Y. K. Gupta (Pro-Chancellor) and Dr. R. P. Singh (Vice-Chancellor). It will not be out of place to mention that the organization of the conference on such a big scale and compilation of this volume would not have been possible without the whole-hearted support of Vice-Chancellor Singh and Dr. M. Al-Lawatia, Head of the Department of Mathematics and Statistics, Sultan Qaboos University, Oman. We also express our gratitude to all those who reviewed the papers and provided us their valuable assistance at all stages, especially to Ms. Meenakshi, Ms. Noor-e-Zahra, Dr. Mani Mehra, Prof. Mushahid Husain, Dr. Khwaja Shahid and Prof. Q. H. Ansari. We also take this opportunity to thank Prof. M. S. Raghunathan (Chairman, Executive Organizing Committee of ICM 2010) and Prof. S. Kesavan (Convener Satellite Conferences of ICM 2010). Valuable cooperation of Ms. E. H. Chionh, World Scientific Publishing, is highly appreciated.

A. H. Siddiqi, R. C. Singh and P. Manchanda

30 December 2010 


\section{FOREWORD}

As scientific disciplines go, Physics, Chemistry, Biology and Mathematics are reasonably well-organized in India. Applied Mathematics, on the other hand, has not yet received its share of recognition. The reason is partly that it continues to be seen as watered down version of Mathematics, or outdated Theoretical Physics, or a somewhat distant — and sometimes irrelevant - cousin of Engineering and Technology. This should change: as the need for modeling and understanding of the increasingly complex phenomena of our times becomes more pressing, so should the role of Applied Mathematics expand. Applied Mathematics as a discipline includes the application of known mathematics to practical and scientific problems as well as the invention of new mathematics with applications in mind.

Applied Mathematics often feeds Mathematics proper, and, indeed, many first-rate mathematics departments and research institutes in the world have begun to appreciate this fact. Indeed, some never wavered in this belief. Needless to say, Applied Mathematics has a vital role to play in diverse areas of engineering, energy, material science, geological and geophysical sciences, biological sciences including medicine, social sciences including economics, and so forth. This is why the work of the Indian Society of Industrial and Applied Mathematics (ISIAM), is very important - especially at a time when the country is engaged in technological rejuvenation. This is indeed why the Society deserves, and needs, your support.

Thanks to Professor Siddiqi, I got involved in this society a few years ago, and wish to take this opportunity to say a few words on the progress made and the work that still remains to be done.

We greatly appreciate the support of the International Mathematical Union, whose main Congress was held in Hyderabad and whose satellite conference was held in Delhi. This volume is the result of the latter. The collection of articles presented in this volume is a measure of the vitality of the community, and of the standard of this conference in particular. We also thank Sharda University, various government agencies which have 
supported this meeting, the constant background support of ICIAM, the support of the international and national communities of mathematicians, and the support of the community as a whole.

Owing to the efforts of the office bearers of this Society, which includes Professors Siddiqi, Gupta, Dikshit, Manchanda and others from the past, the scientific meetings of ISIAM are constantly improving: the invited talks are usually first-rate, Zakir Husain awardees are of high caliber, the fundraising has become less stochastic, ISIAM's reach and scope have been expanding, and so forth. I congratulate the Society on its emergence as an increasingly professional organization which has been forging ever strengthening links within India and internationally. Let us not forget, however, that there are many aspects which need improvement. It is these aspects to which I will now draw attention, while being fully aware that the outlook towards reaching these goals appears good.

The following aspects have not changed much. Applied Mathematics is still not yet a well-organized and well-knit community within the country, in comparison with its importance. The participation of the members of this community in the technological development within the country is yet to reach a critical level; and applied mathematics graduate students, whose numbers seem to have increased recently, do not find satisfying jobs quickly enough. Applied Mathematics in India has not yet made central contributions to the grand challenges of our times: climate change, new materials, energy, problems of megacities, ground water depletion, spread of infectious diseases, ever-changing economic environment, security, etc. The overall quality of research in Applied Mathematics, whether on the applications front or in feeding mathematics proper, has not yet reached the high level that it should. The connection between the methods of Applied Mathematics and the advances on the computational front is still not strong. There is a real opportunity here for the Applied Mathematics community because of the confluence of the importance of the subject and the timeliness and availability of resources. We could make this an exciting time for us and for the subject.

Please don't get me wrong or think of me as being overly critical. I believe that there are accomplished applied mathematicians in this country. Indeed, ISIAM has itself honored a number of them - including some at this meeting. There are also some first-rate students in applied mathematics. My point is simply that the quality is not sufficiently uniform, that the average level is not sufficiently high, the numbers too small and the visibility too low. We should strive to improve the situation on all fronts. 
In this task, the role of senior mathematicians is to open up new avenues, inspire younger people and mentor them well, in both their research and careers, and eventually build groups in which rigor, accomplishment, creativity and quality are valued above all, and the potential of the younger people can be explored fully and without hurdles. There are some wonderful people of this sort in the country but there are not enough of them. The role of young mathematicians is to take serious interest in their subject, develop technical skills of high order, and do competitive mathematics. They should understand that mathematics is not a local activity in which to dabble, but is an international arena in which one has to play and excel. Recognition will come in due course: as in other arenas of human activity, there are many quirks that may seem discouraging, but one has to look past them.

There is no ready-made recipe for this situation to work itself out; it requires hard and dedicated work. The first important need, however, is the spirit of learning, of placing one's own work as part of a bigger landscape, and the willingness to work single-mindedly towards creating one's own landscape. Hardly are great things possible without this spirit and hard work - especially in mathematics. While it is not possible to do good Applied Mathematics without knowing Mathematics, it is not enough to know good Mathematics; one has to move in circles where applications present themselves as opportunities.

The second important element is to ensure that there is adequate support for younger researchers. This is where ISIAM can and should do more. It ought to build not only the spirit of doing Applied Mathematics and create a culture in which ideas and their interplay with applications are valued, but also enable better support structure for the discipline. It will have done very well then. I have no doubt that its work will be amply rewarded. 
This page is intentionally left blank 


\section{CONTENTS}

Preface $\quad$ V

Foreword

Affiliation of Contributors $\quad$ xvii

\section{Part A Invited Talk}

1. In Appreciation of Dr Zakir Husain Award

M. Zuhair Nashed

2. Kinematical Conservation Laws (KCL): Equations of Evolution of Curves and Surfaces

K. R. Arun and P. Prasad

3. Systematic Discretization of Input/Output Maps and

Control of Partial Differential Equations

J. Heiland, V. Mehrmann and M. Schmidt

4. Vertex Couplings in Quantum Graphs: Approximations by Scaled Schrödinger Operators

P. Exner

5. Complexity Leads to Randomness in Chaotic Systems

R. Lozi

6. Mathematical Modeling for Unifying Different Branches of Science, Engineering and Technology

N. Rudraiah

7. On Equivalence Transformations and Exact Solutions of a

Helmholtz Type Equation

O. P. Bhutani and L. R. Chowdhury 
8. Cognitive Radio: State-of-the-Art and Mathematical Challenges

T. Nadkar, V. Thumar, A. Patel, Md. Z. Ali Khan, U. B. Desai and S. N. Merchant

\section{Part B Thematic Reviews}

9. Inverse Problems of Parameter Identification in Partial Differential Equations

B. Jadamba, A. A. Khan and M. Sama

10. Finite Element Methods for HJB Equations

M. Boulbrachene

11. Dynamics and Control of Underactuated Space Systems

K. D. Kumar and Godard

12. Some New Classes of Inverse Coefficient Problems in Engineering Mechanics and Computational Material Science Based on Boundary Measured Data

A. Hasanov

13. Some Recent Developments on Mathematical Aspect of Wavelets

P. Manchanda and Meenakshi

14. Relevance of Wavelets and Inverse Problems to Brain

A. H. Siddiqi, H. K. Sevindir, Z. Aslan and C. Yazici

15. Wavelets and Inverse Problems

K. Goyal and M. Mehra

16. Optimization Models for a Class of Structured Stochastic Games

S. K. Neogy, S. Sinha, A. K. Das and A. Gupta

\section{Part C Contributory Talks}

17. Predator-Prey Relations for Mammals where

Prey Suppress Breeding

Q. J. Khan and M. Al-Lawatia 
18. SEI Model with Varying Transmission and Mortality Rates G. Rost

19. Trajectories and Stability Regions of the Lagrangian Points in the Generalized Chermnykh-Like Problem B. S. Kushvah

20. MHD Flow Past an Infinite Plate Under the Effect of Gravity Modulation

S. Wasu and S. C. Rajvanshi

List of Invited Speakers and Participants

Index 
This page is intentionally left blank 


\section{Affiliation of Contributors}

\begin{tabular}{|c|c|c|}
\hline S.No. & Name & Address \\
\hline 1. & Prof. M. Zuhair Nashed & $\begin{array}{l}\text { Department of Mathematics, University of Central } \\
\text { Florida, Orlando, Florida, USA } \\
\text { Email:znashed@ @mail.ucf.edu }\end{array}$ \\
\hline \multirow[t]{2}{*}{2.} & Prof. Phoolan Prasad & $\begin{array}{l}\text { Department of Mathematics, } \\
\text { Indian Institute of Science, Bangalore-560012, } \\
\text { India. Email: prasad@ @math.iisc.ernet.in }\end{array}$ \\
\hline & Dr. K. R. Arun & $\begin{array}{l}\text { Department of Mathematics, } \\
\text { Indian Institute of Science, Bangalore-560012, } \\
\text { India }\end{array}$ \\
\hline \multirow[t]{3}{*}{3.} & Prof. V. Mehrmann & $\begin{array}{l}\text { Institute of Mathematics, Technical University } \\
\text { Berlin } 10623 \text { Berlin, Germany } \\
\text { Email: mehrmann@math.tu-berlin.de }\end{array}$ \\
\hline & Dr. J. Heiland & $\begin{array}{l}\text { Institute of Mathematics, Technical University } \\
\text { Berlin 10623 Berlin, Germany } \\
\text { Email: heiland@math.tu-berlin.de }\end{array}$ \\
\hline & Dr. M. Schmidt & $\begin{array}{l}\text { GE Global Research Centre, } 85748 \text { Garching bei } \\
\text { Munchen, Germany. } \\
\text { Email: mail@schmidt-michael.de }\end{array}$ \\
\hline 4. & Prof. Pavel Exner & $\begin{array}{l}\text { Doppler Institute for Mathematical Physics and } \\
\text { Applied Mathematics, Czech Technical University, } \\
\text { Brehova7,11519 Prague, Czech Republic \& } \\
\text { Department of Theoretical Physics, Nuclear } \\
\text { Physics Institute, Czech Academy of Sciences, } \\
\text { 25068 Rez near Prague, Czech Republic } \\
\text { Email: exner@ujf.cas.cz }\end{array}$ \\
\hline 5. & Prof. R. Lozi & $\begin{array}{l}\text { Laboratory J.A.Dieudonne, UMR CNRS6621, and } \\
\text { Institute Universitaire de Formation des Maitres } \\
\text { Celestin Freinet, University of Nice Sophia- } \\
\text { antipolis, France. Email: R.Lozi @ unice.fr }\end{array}$ \\
\hline 6. & Prof. N. Rudraiah & $\begin{array}{l}\text { National Research Institute of Applied } \\
\text { Mathematics(NRIAM) JayaNagar Banalore- } \\
560070 \text { and UGC-CAS in Fluid Mechanics, } \\
\text { Department of Mathematics, Bangalore University, } \\
\text { Bangalore-560070. } \\
\text { Email: rudraiahn@ @otmail.com }\end{array}$ \\
\hline \multirow[t]{2}{*}{7.} & Prof. O. P. Bhutani & $\begin{array}{l}\text { Honorary Scientist(INSA), B-1/1057, Vasant Kunj, } \\
\text { New Delhi- } 110070 \text {, India. }\end{array}$ \\
\hline & Dr. L. R. Chowdhury & B1K, 136 \# 101-40, Vishan Ring Road, Singapore \\
\hline \multirow[t]{3}{*}{8.} & Dr. Taskeen Nadkar & $\begin{array}{l}\text { Department of Electrical Engineering, IIT } \\
\text { Bombay, Maharashtra, India. } \\
\text { Email: taskenn@ee.iitb.ac.in }\end{array}$ \\
\hline & Dr. Vinay Thumar & $\begin{array}{l}\text { Department of Electrical Engineering, IIT } \\
\text { Bombay, Maharashtra, India. } \\
\text { Email: vinay_thumar@ee.iitb.ac.in }\end{array}$ \\
\hline & Dr. Aaqib Patel & Department of Electrical Engineering, IIT \\
\hline
\end{tabular}




\begin{tabular}{|c|c|c|}
\hline & & $\begin{array}{l}\text { Bombay, Maharashtra, India. } \\
\text { Email: aaqib@ee.iitb.ac.in }\end{array}$ \\
\hline & Dr. Md. Zafar Ali Khan & $\begin{array}{l}\text { IIT Hyderabad, Ordnance Factory Estate, Andhra } \\
\text { Pradesh, India. Email: zafar@ iith.ac.in }\end{array}$ \\
\hline & Prof. U. B. Desai & $\begin{array}{l}\text { IIT Hyderabad, Ordnance Factory Estate, Andhra } \\
\text { Pradesh, India. Email: ubdesai@ iith.ac.in }\end{array}$ \\
\hline & Dr. S. N. Merchant & $\begin{array}{l}\text { Department of Electrical Engineering, IIT } \\
\text { Bombay, Maharashtra, India. } \\
\text { Email: merchant@ee.iitb.ac.in }\end{array}$ \\
\hline \multirow[t]{3}{*}{9.} & Dr. A. A. Khan & $\begin{array}{l}\text { School of Mathematical Sciences, Rochester } \\
\text { Institute of Technology, Rohester, New } \\
\text { York,14623,USA Email: aaksma@ rit.edu }\end{array}$ \\
\hline & Dr. B. Jadamba & $\begin{array}{l}\text { School of Mathematical Sciences, Rochester } \\
\text { Institute of Technology, Rohester, New } \\
\text { York,14623,USA. Email: bxjsma@ @rit.edu }\end{array}$ \\
\hline & Dr. M. Sama & $\begin{array}{l}\text { Department de Mathematica Applicado } \\
\text { Universidad National de Educacion a Distancia } \\
\text { Madrid, Spain. Email: msama@ind.uned.es }\end{array}$ \\
\hline 10. & Dr. M. Boulbrachene & $\begin{array}{l}\text { Department of Mathematics and Statistics, Sultan } \\
\text { Qaboos University, Muscat, Oman. } \\
\text { Email: boulbrac@squ.edu.om }\end{array}$ \\
\hline \multirow[t]{2}{*}{11.} & Prof. K. D. Kumar & $\begin{array}{l}\text { Department of Aerospace Engineering, Ryerson } \\
\text { University, } 350 \text { Victoria Street, Toronto, Ontorio } \\
\text { M5b2K3,Canada. } \\
\text { Email:kdkumar@ ryerson.ca }\end{array}$ \\
\hline & Dr. Godard & $\begin{array}{l}\text { Department of Aerospace Engineering, Ryerson } \\
\text { University, } 350 \text { Victoria Street, Toronto, Ontorio } \\
\text { M5b2K3,Canada }\end{array}$ \\
\hline 12. & Prof. Alemdar Hasanov & $\begin{array}{l}\text { Department of Mathematics and Computer } \\
\text { Science, Izmir University,35350,Izmir,Turkey } \\
\text { Email: alemdar.hasanoglu@izmir.edu.tr }\end{array}$ \\
\hline \multirow[t]{2}{*}{13} & Prof. P. Manchanda & $\begin{array}{l}\text { Department of Mathematics, Guru Nanak Dev } \\
\text { University, Amritsar, India } \\
\text { Email: pmanch2k1@yahoo.co.in }\end{array}$ \\
\hline & Ms. Meenakshi & $\begin{array}{l}\text { Dev Samaj College for Women, Ferozepur, India } \\
\text { Email: meenakshi_wavelets@ yahoo.com }\end{array}$ \\
\hline \multirow[t]{4}{*}{14.} & Prof. A. H. Siddiqi & $\begin{array}{l}\text { Deparment of Mathematics, Sharda University, } \\
\text { Greater Noida, India } \\
\text { Email:siddiqi.abulhasan@gmail.com, }\end{array}$ \\
\hline & Dr. H. Kodal Sevindir & $\begin{array}{l}\text { Department of Mathematics, University of } \\
\text { Kocaeli, Kocaeli, Turkey } \\
\text { Email: hkodal@ @ocaeli.edu.tr }\end{array}$ \\
\hline & Prof. Z. Aslan & $\begin{array}{l}\text { Department of Computer Engineering, Istanbul } \\
\text { Aydin University, Istanbul, Turkey. } \\
\text { Email: zaferaslan@aydin.edu.tr }\end{array}$ \\
\hline & Dr. C. Yazici & $\begin{array}{l}\text { Department of Mathematics, University of } \\
\text { Kocaeli, Kocaeli, Turkey } \\
\text { Email: cuneyt.yazici@ kocaeli.edu.tr }\end{array}$ \\
\hline
\end{tabular}




\begin{tabular}{|c|c|c|}
\hline \multirow[t]{2}{*}{15.} & Ms Kavita Goyal & $\begin{array}{l}\text { Department of Mathematics, Indian Institute of } \\
\text { Technology Delhi, Hauz Khas,New-Delhi-110116 } \\
\text { Email; kavita-ma@student.iitd.ac.in }\end{array}$ \\
\hline & Dr. Mani Mehra & $\begin{array}{l}\text { Department of Mathematics, Indian Institute of } \\
\text { Technology Delhi, Hauz Khas,New-Delhi-110116 } \\
\text { Email: mmehra@maths.iitd.ac.in }\end{array}$ \\
\hline \multirow[t]{4}{*}{16.} & Prof. S. K. Neogy & $\begin{array}{l}\text { Indian Statistical Institute Institute, } 7 \text { SJS } \\
\text { Sansanwal Marg, New-Delhi -110016, India } \\
\text { Email: skn@isid.ac.in }\end{array}$ \\
\hline & Prof. Sagnik Sinha & $\begin{array}{l}\text { Jadavpur University,Kolkata-700032,India } \\
\text { Email:sagnik62@yahoo.co.in }\end{array}$ \\
\hline & Dr. A. K. Das & $\begin{array}{l}\text { Indian Statistical Institute 203,B.T.Road,Kolkata- } \\
\text { 700108,India } \\
\text { Email:akdas@isical.ac.in }\end{array}$ \\
\hline & Dr. A. Gupta & ISI,Kolkata. Email: agupta@ isical.ac.in \\
\hline \multirow[t]{2}{*}{17.} & Dr. Q. J. A. Khan & $\begin{array}{l}\text { Department of Mathematics and Statistics, Sultan } \\
\text { Qaboos University, P.O.Box, Al-Khodh123, } \\
\text { Sultanate of Oman }\end{array}$ \\
\hline & Dr. M. Al-Lawatia & $\begin{array}{l}\text { Department of Mathematics and Statistics, Sultan } \\
\text { Qaboos University, P.O.Box, Al-Khodh123, } \\
\text { Sultanate of Oman }\end{array}$ \\
\hline 18. & Dr. Gergely Rost & $\begin{array}{l}\text { Analysis and Stochastics Research Group } \\
\text { Hungarian Academy of Sciences, Bolyai Institute, } \\
\text { University of Szeged,Hungary, Aradi vertanuk } \\
\text { tere1,H-6725,Szeged,Hungary, } \\
\text { Email: rost@ math.u-szeged.hu }\end{array}$ \\
\hline 19. & $\begin{array}{l}\text { Dr. Badam Singh } \\
\text { Kushvah }\end{array}$ & $\begin{array}{l}\text { Department of Applied Mathematics, Indian } \\
\text { School of Mines,Dhanbad-826004,Jharkhand,India } \\
\text { Email: bskush@gmail.com, } \\
\text { kushvah.bs.am@ismdhanbad.ac.in }\end{array}$ \\
\hline \multirow[t]{2}{*}{20.} & Ms Sargam Wasu & $\begin{array}{l}\text { Department of Applied Sciences, Gurukal } \\
\text { Vidyapeeth Institute of Engineering and } \\
\text { Technology, Sector 7, Banur, Dist.Patiala, Punjab, } \\
\text { India. Email: sargam15@ @rediffmail.com }\end{array}$ \\
\hline & Prof. S. C. Rajvanshi & $\begin{array}{l}\text { Department of Applied Sciences, Gurukal } \\
\text { Vidyapeeth Institute of Engineering and } \\
\text { Technology, Sector 7, Banur, Dist.Patiala, Punjab, } \\
\text { India. }\end{array}$ \\
\hline
\end{tabular}

